\title{
Review article: Risks of anemia and related management strategies: can perioperative blood management improve patient safety?
}

\section{Article de synthèse: Risques d'anémie et stratégies de prise en charge : la gestion périopératoire du sang peut-elle améliorer la sécurité du patient?}

\author{
Gregory M. T. Hare, MD, PhD • John Freedman, MD • \\ C. David Mazer, MD \\ Received: 21 June 2012/ Accepted: 27 November 2012/Published online: 25 January 2013 \\ (C) Canadian Anesthesiologists' Society 2013
}

\begin{abstract}
Purpose Anemia in both acute and chronic conditions is associated with an increased risk of organ injury (brain, heart, kidney) and mortality. Thus, anemia is not "safe". Impairment of tissue oxygen delivery likely contributes as a central mechanism; however, the existing treatments for anemia (i.e., transfusion, erythropoiesis stimulating agents, blood substitutes) have not produced a demonstrable improvement in patient outcomes despite their efficacy to increase blood oxygen content. Indeed, transfusion of red blood cells (RBCs) has been attributed to increase mortality in non-bleeding patients. Thus, the pathophysiology of anemia-induced morbidity and mortality and its treatments are complex and incompletely understood. New knowledge continues to emerge regarding the cellular mechanisms that maintain oxygen homeostasis during anemia. Nevertheless, the application of this knowledge has not yet
\end{abstract}

G. M. T. Hare, MD, PhD - C. David Mazer, MD

Department of Anesthesia, Keenan Research Centre in the Li Ka Shing Knowledge Institute, St. Michael's Hospital, University of Toronto, Toronto, ON, Canada

G. M. T. Hare, $\mathrm{MD}, \mathrm{PhD}$ - C. David Mazer, $\mathrm{MD}$

Department of Physiology, University of Toronto, Toronto, ON, Canada

J. Freedman, MD

Division of Hematology, Department of Medicine, St. Michael's Hospital, University of Toronto, Toronto, ON, Canada

G. M. T. Hare, MD, PhD ( $\square)$

Department of Anesthesia and Physiology, St. Michael's

Hospital, University of Toronto, 30 Bond Street, Toronto, ON

M5B 1W8, Canada

e-mail: hareg@smh.ca led to improvements in patient outcomes. As both anemia and transfusion are associated with increased mortality, utilization of multimodal patient blood management strategies may be effective in avoiding both of these predictors of adverse outcomes. We propose to review new strategies to avoid both anemia and transfusion with the goal of improving patient outcomes and safety.

Principal findings We reviewed several approaches that utilize patient blood management to improve patient outcomes, including 1) characterization of biomarkers of anemia-induced tissue hypoxia to identify appropriate patient-specific treatment thresholds or hemoglobin $(\mathrm{Hb})$ triggers; 2) development of adequately powered clinical trials that will help to define appropriate guidelines for the perioperative treatment of anemia and optimal $\mathrm{Hb}$ thresholds for transfusion of RBCs in specific patient populations; and 3) demonstration that an established blood conservation program (ONTraC) can reduce $R B C$ transfusion and its associated adverse outcomes.

Conclusions Anemia is associated with increased morbidity and mortality. Ongoing initiatives to treat anemia and optimize patient blood management may improve patient outcomes. A broader application of these approaches may improve the overall safety of anesthesia and surgery for patients with anemia.

\section{Résumé}

Objectif L'anémie, qu'elle soit aiguë ou chronique, est associée à un risque accru d'atteinte des organes (cerveau, cour, reins) et à une mortalité plus élevée. Ainsi, l'anémie n'est pas « sans risques ». Un déficit d'apport d'oxygène aux tissus est probablement un mécanisme contributif majeur. Cependant, les traitements actuels de l'anémie (c'est-à-dire les transfusions, les agents stimulant 
l'érythropoïse, les produits de substitution du sang) n'ont pas apporté une amélioration démontrable du pronostic des patients en dépit de leur efficacité pour augmenter le contenu en oxygène du sang. En fait, on a attribuéaux transfusions de globules rouges un accroissement de la mortalité chez les patients non hémorragiques. Ainsi, la physiopathologie de la morbidité et de la mortalité induites par l'anémie est complexe et n'est pas encore complètement élucidée. De nouvelles connaissances continuent à apparaître concernant les mécanismes cellulaires qui maintiennent l'homéostasie de l'oxygène au cours de l'anémie. Néanmoins, la mise en cuvre de ce savoir n'a pas encore mené à des améliorations en termes de pronostic. L'anémie et la transfusion étant toutes deux associées à une augmentation de la mortalité, l'utilisation de stratégies multimodales de gestion du sang des patients peut s'avérer utile pour éviter ces deux éléments prédictifs d'évolution défavorable. Nous proposons d'analyser de nouvelles stratégies pour éviter, à la fois, l'anémie et les transfusions dans le but d'ameliorer le pronostic et la sécurité des patients.

Constatations principales Nous avons examiné plusieurs approches faisant appel à la gestion du sang des patients pour améliorer leur pronostic, y compris 1) la détermination de biomarqueurs d'hypoxie tissulaire induite par l'anémie pour identifier des seuils de traitement spécifiques aux patients ou des niveaux d'hémoglobine (Hb) critiques, 2) l'élaboration d'études cliniques ayant une puissance suffisante pour contribuer à définir des directives appropriées pour le traitement périopératoire de l'anémie et la définition de seuils optimaux d'hémoglobine pour la transfusion de globules rouges dans des populations particulières de patients, et 3) la démonstration qu'un programme organisé de conservation du sang (ONTraC) peut limiter les transfusions de globules rouges et les conséquences néfastes qui lui sont associées.

Conclusions L'anémie est associée à une augmentation de la morbidité et de la mortalité. Les initiatives en cours pour traiter l'anémie et optimiser la gestion du sang des patients peuvent améliorer l'évolution de ces derniers. Une application plus large de ces approches peut améliorer la sécurité globale de l'anesthésie et de la chirurgie pour les patients ayant une anémie.

Since the inception of our specialty, improving the quality and safety of perioperative care has been a central goal of anesthesiologists. ${ }^{1,2}$ While diverse and multifactoral components are included in the definition of quality, an integral part of all assessments of quality improvement in medicine is the element of improved safety. ${ }^{1,2}$ Accordingly, improving patient safety is one of the cornerstones by which we can assess the level of the quality of care we provide. Within the practice of medicine, the definition of safety usually includes the avoidance of events or circumstances that cause harm or injury (i.e., morbidity and mortality). In this paper, we review data that suggest anemia is an unsafe condition associated with increased adverse outcomes. We also explore a number of approaches to treat anemia and minimize anemia-induced morbidity and mortality with the long-term goal of improving patient safety.

\section{Why is anemia unsafe?}

As recently reviewed, anemia is a global health problem affecting an estimated $25 \%$ of the world's population. ${ }^{3}$ Iron deficiency is the contributing etiology in about $50 \%$ of cases. ${ }^{4}$ In surgical patients, the prevalence of anemia is estimated to be as high as 20-30\% for non-cardiac surgery ${ }^{5,6}$ and more than $50 \%$ for cardiac surgical patients. ${ }^{7}$ About $30 \%$ of these anemic patients have either iron deficiency anemia or anemia of chronic disease. ${ }^{8}$ In these patients, even mild to moderate degrees of anemia have been associated with adverse outcomes, including renal injury, stroke, and death. ${ }^{5,7,9,10}$ Furthermore, our basic science studies ${ }^{11,12}$ and new translational clinical data support the hypothesis that the risk of anemia-induced organ injury (myocardial infarction and stroke) and mortality are accentuated by commonly utilized therapies that limit cardiovascular responses ( $\beta$-blockade). ${ }^{13-15}$ As such, these data support the conclusion that perioperative anemia is unsafe.

Evidence maintains that management of these patients with iron and limited treatment with erythropoiesis-stimulating agent (ESA) can increase the hemoglobin $(\mathrm{Hb})$ level preoperatively and reduce transfusion. ${ }^{16,17}$ Most trials have utilized allogeneic red blood cell (RBC) transfusion and ESAs as the main modalities of treatment. However, both of these therapies have been associated with increased morbidity, including an increased incidence of thrombosis and cancer progression, infection, length of stay, and mortality. 3,18,19 Thus, in some respects, both anemia and some of its treatments can be viewed as being unsafe. More data are required to determine which therapies can improve outcomes, including event-free survival in specific patient populations.

\section{What is the mechanism of anemia-induced mortality?}

As with many disease processes, developing effective treatments for anemia-induced morbidity and mortality requires specific knowledge of the pathophysiology; however, we do not yet have a clear understanding of theses mechanisms. It has been assumed that severe anemia leads 
to inadequate tissue oxygen delivery, resulting in tissue hypoxia, organ failure, and death (Fig. 1). This is supported by the observation that acute anemia results in an increase in mortality that is proportional to the reduction in $\mathrm{Hb}^{20}$ Consistent with this observation, the mean lethal $\mathrm{Hb}$ level has been estimated to be near $25 \mathrm{~g} \cdot \mathrm{L}^{-1}$ in humans and animals. ${ }^{3,21}$ In less severe chronic anemia, however, some authors have proposed that anemia may be adaptive. ${ }^{22}$ In addition to these opposing views, it is also possible that anemia may be merely associated with, rather than causative of, multisystem organ failure and death (Fig. 1). Thus, a more complete understanding of the mechanisms and effects of anemia is required to inform clinical practice effectively.

As defined by studies in animals and humans, acute reduction in $\mathrm{Hb}$ is sensed at the cellular level and leads to adaptive cardiovascular responses to optimize tissue oxygen delivery. ${ }^{3,23,24}$ These responses include 1) a characteristic increase in cardiac output $(\mathrm{CO})$ that is proportional to the degree of anemia; 2) a reduction in systemic vascular resistance with organ-specific vasodilation to facilitate preferential perfusion of vital organs, including the heart and brain; and 3) an increase in tissue oxygen extraction. In addition, anemia results in the activation of hypoxic cellular mechanisms, including neuronal nitric oxide synthase (nNOS) and hypoxia inducible factor (HIF), with the purpose of maintaining oxygen homeostasis and sustaining organism survival. ${ }^{21,25}$ These mechanisms are thought to be adaptive because the genetic deletion of nNOS results in severe attenuation of the HIF response and increased mortality in acutely anemic mice. Specifically, anemic mice deficient in nNOS, an enzyme that produces nitric oxide, cannot generate the expected increase in $\mathrm{CO}$ and have a profoundly attenuated HIF response to anemia. These deficiencies contribute to increased mortality in these mice, which die earlier and at a higher $\mathrm{Hb}$

\section{Anemia and Mortality: Association or Causation?}

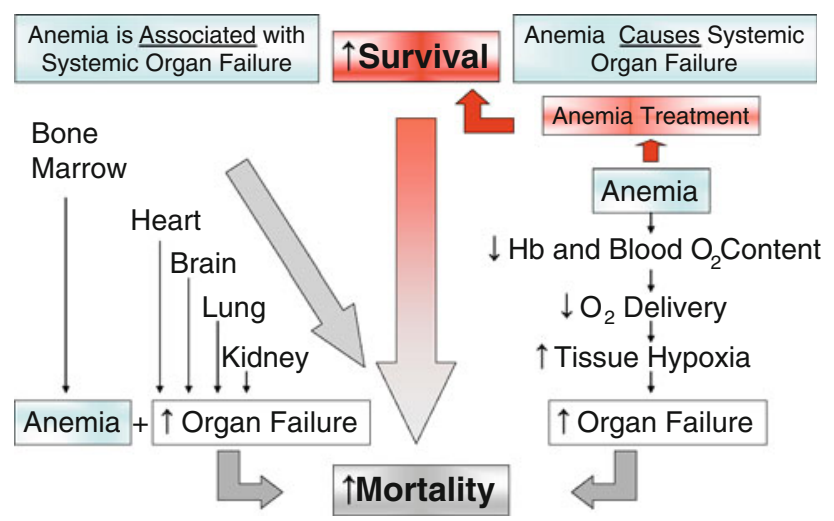

Fig. 1 Potential pathways by which treatment of anemia may affect survival concentration in a model of acute anemia. ${ }^{21}$ The physiologic mechanisms by which nNOS-derived nitric oxide signalling supports survival during acute anemia include 1) regulation of the increase in $\mathrm{CO}$ required to maintain global tissue oxygen delivery during anemia; and 2) priming or amplifying the hypoxia inducible factor- $1 \alpha$ (HIF-1 $\alpha$ ), a transcription factor regarded as the master regulator of adaptive hypoxic cellular responses. ${ }^{26}$ Thus, nNOS regulates both the acute cardiovascular responses that optimize oxygen delivery to vital organs and the ability of each cell to adapt to reduced levels of oxygen. Together, these mechanisms support the maintenance of oxygen homeostasis during acute anemia. In the absence of these responses, healthy young mice experience a shift in their mean lethal $\mathrm{Hb}$ concentration from $25 \mathrm{~g} \cdot \mathrm{L}^{-1}$ to a higher value near $35 \mathrm{~g} \cdot \mathrm{L}^{-1} \cdot{ }^{21}$ Experimental models have shown that these hypoxic cellular responses are also upregulated during chronic anemia ${ }^{27}$ and in older hypertensive rodents, ${ }^{28}$ suggesting that they may have relevance to both the pediatric and the older adult patient populations that undergo anesthesia for surgical treatment. The overall conclusion from current experimental models strongly suggests that impaired oxygen delivery and tissue hypoxia contribute to increased mortality during acute anemia.

\section{Why have current treatments of anemia not improved patient outcomes and safety?}

If acute reductions in blood oxygen content and tissue oxygen delivery are responsible for increased mortality, then treatments that increase blood oxygen content should improve survival. To date, however, the collective evidence has failed to show that treatments of anemia can improve survival. As mentioned above, RBC transfusions, ESAs and hemoglobin-based oxygen carriers (HBOC) have all been shown to increase blood oxygen content but without an overall improvement in survival. Paradoxically, each of these treatments has been associated with increased morbidity and mortality. ${ }^{3,18,19,29}$ Although the mechanisms are likely complex, potential factors contributing to these adverse outcomes include RBC storage lesion (RBC transfusion), upregulation of prothrombotic mechanisms (ESAs), and increased systemic nitric oxide binding (HBOCs). With respect to ESA therapy, the negative outcome data for medical patients may have unnecessarily discouraged the use of erythropoietin in some surgical patient populations. For example, more recent clinical studies have shown that long-term ESA use does not necessarily improve survival but does increase the risk of thrombotic complications and may enhance cancer progression. ${ }^{18,19}$ On the other hand, previous systematic reviews in cardiac and non-cardiac surgery have shown 
that ESA therapy can reduce $\mathrm{RBC}$ transfusions without a resultant increase in thrombotic complications. ${ }^{16,30,31}$ This discrepancy may be due to the fact that these patients received short-term therapy and anticoagulation in the perioperative period. Although the use of iron and ESA has been shown to be efficacious in reducing red blood cell transfusions, it is unclear whether this effect is associated with a reduction in adverse outcomes, including mortality. Finally, differences in the etiology of anemia and variability in the optimal $\mathrm{Hb}$ concentration in different patient populations and in individual patients may require more tailored treatment strategies to improve the outcomes of anemic patients. Therefore, novel approaches to the treatment and management of preoperative anemia must be sought.

\section{Can patient-specific $\mathrm{Hb}$ thresholds for tissue hypoxia be determined?}

In surgical patients who experience acute blood loss, the decrease in $\mathrm{Hb}$ concentration is proportional to the increase in mortality, with an estimated mean lethal $\mathrm{Hb}$ value near $25 \mathrm{~g} \cdot \mathrm{L}^{-1} ;^{3}$ however, the determinants of any one individual patient's Hb threshold for tissue hypoxia are likely to be multifactoral and highly variable. For example, one case report summarized the intact survival of a patient with an acute nadir $\mathrm{Hb}$ near $\sim 7 \mathrm{~g} \cdot \mathrm{L}^{-1}$. This demonstrates that individuals can survive at profoundly different $\mathrm{Hb}$ thresholds during acute anemia and provides the proof of principle that the impact of anemia is variable and patient-specific. ${ }^{32}$ By contrast, some patients undergoing cardiac surgery have an increased risk of mortality when their preoperative $\mathrm{Hb}$ levels are lower than $100 \mathrm{~g} \cdot \mathrm{L}^{-1} \cdot 9,10$ Thus, patients may be able to tolerate different levels of $\mathrm{Hb}$ reduction based on their genetic background, level of conditioning, and associated comorbidities. Therefore, treatments that focus on one level of $\mathrm{Hb}$ for a population may not be appropriate for all individuals in that population. $^{33}$

Currently, we have no objective and reliable means of determining when an individual patient is at risk of anemiainduced tissue hypoxia, organ injury, and death. ${ }^{34} \mathrm{We}$ transfuse RBCs to restore adequate tissue $\mathrm{O}_{2}$ delivery but haven't devised clinical methods to measure tissue $\mathrm{O}_{2}$ tension accurately after transfusion. New methods for assessing the adequacy of tissue oxygen delivery after red cell transfusion include near infrared spectroscopy, ${ }^{35,36}$ positron emission tomography, ${ }^{37}$ functional magnetic resonance imaging, and invasive oxygen electrodes. ${ }^{38,39}$ These measurements assess tissue $\mathrm{O}_{2}$ tension directly or the degree of $\mathrm{O}_{2}$ extraction and oxyhemoglobin saturation. While some studies using these approaches showed improved $\mathrm{O}_{2}$ delivery and tissue partial pressure of $\mathrm{O}_{2}$ with transfusion, others did not. Furthermore, these methods for assessing anemia-induced tissue hypoxia or the impact of $\mathrm{RBC}$ transfusion are not yet in general use.

One aspect of our research has been to identify adaptive mechanisms that help mammals survive low $\mathrm{Hb}$ levels. Based on this research, we have provided animal and human data that assess potential specific biomarkers of anemia-induced tissue hypoxia. These data included biomarkers of tissue hypoxia (systemic erythropoietin, cerebral near-infrared spectroscopy); microvascular oxyhemoglobin desaturation (altered plasma nitrite/nitrate ratios), and enhanced nitric oxide production and/or activation (plasma methemoglobin). ${ }^{40,41}$ Prospective studies are currently underway to identify whether such biomarkers of anemia-induced tissue hypoxia can accurately predict adverse clinical outcomes. With these data in hand, trials can then be designed to identify patient-specific $\mathrm{Hb}$ thresholds for tissue hypoxia, and this approach can then be used to determine if specific treatments improve patient outcomes.

\section{Can we define anemia treatment thresholds in specific patient populations?}

Since publication of the Transfusion Requirements in Critical Care (TRICC) trial, ${ }^{42}$ we have appreciated that some patients can tolerate a lower level of $\mathrm{Hb}$. This finding has changed patient care and reduced unnecessary transfusion of RBCs. The recent transfusion guidelines from the American Association of Blood Banks provides one of the most up-to-date syntheses of the literature with recommendations for specific transfusion thresholds. ${ }^{43}$ These guidelines provide a starting point from which to consider the treatment of the anemic patient. As acknowledged, the values of $\mathrm{Hb}$ triggers differ amongst different patient populations. For example, patients with acute cardiac syndromes, ${ }^{44}$ neurotrauma, ${ }^{45}$ or comorbidities associated with advanced age may require higher $\mathrm{Hb}$ levels. ${ }^{46}$ Interestingly, this perspective may be reflected in the progressive increase in both the $\mathrm{Hb}$ threshold for treatment and the average $\mathrm{Hb}$ in the restrictive arms of subsequent transfusion trials $\left(\mathrm{Hb} \sim 90 \mathrm{~g} \cdot \mathrm{L}^{-1}\right)$ (Fig. 2), although much of this difference can be attributed to differences in study designs.

Based on evidence that patients with unstable coronary syndromes may require a higher "safe" Hb level, transfusion trials have been completed in patients undergoing cardiac surgery. Although designed as a non-inferiority trial, data presented in the Transfusion Requirements after Cardiac Surgery (TRACS) trial suggest that patients in the restrictive arm had a trend toward increased mortality when compared with patients in the liberal arm. ${ }^{47}$ This finding is 


\section{Upward Migration of Hemoglobin ( $\mathrm{Hb})$ Trigger}

\begin{tabular}{|lrlll|}
\hline $\begin{array}{l}\text { Trigger Hct } \\
\text { or } \mathrm{Hb}\end{array}$ & $\mathrm{Hb} \sim 80$ & $\mathrm{Hb} 70$ & $\begin{array}{l}\text { Hct 24\% } \\
(\mathrm{Hb} \sim 75)\end{array} \quad \mathrm{Hb} \sim 80 \quad \mathrm{Hb} \sim 70 / 75$ \\
\hline
\end{tabular}

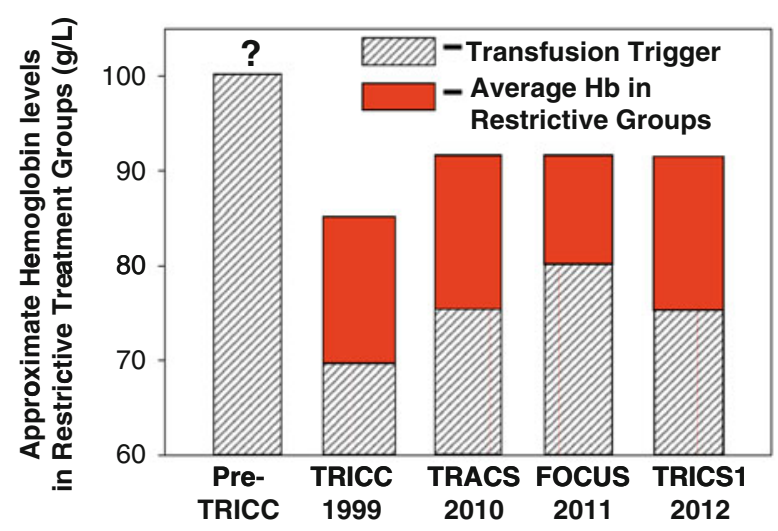

Fig. 2 Depiction of average hemoglobin levels and transfusion triggers in the restrictive arms of completed transfusion trials showing an upward trend in the average level of hemoglobin achieved in the restrictive arms of each study. The figure was derived from generalized and modified data presented in references $42,46-48$

supported by data from the Transfusion Requirements in Cardiac Surgery 1 (TRICS1) trial in which patients in the restricted arm had about twice the number of adverse events compared with patients in the liberal transfusion arm. ${ }^{48}$ Although neither trial was powered to detect differences in clinical outcomes, they emphasize the importance of determining whether patients undergoing cardiac surgery may require a higher level of $\mathrm{Hb}$. In addition, the impact of factors, such as age of blood, RBC storage lesion, increased oxygen affinity and fragility of RBC membranes, and altered nitric oxide binding capacity may also contribute to the lack of a positive impact of RBC transfusion on patient outcome. Adequately powered clinical trials are needed to determine which surgical patients would benefit, or be harmed, from a higher transfusion threshold and to determine the "safe" transfusion thresholds for specific patient populations, including patients undergoing cardiac surgery and those with neurological injury.

\section{Can patient blood management and perioperative blood conservation improve safety?}

Patient blood management can be defined as a multidisciplinary and multimodal approach to treat anemia, prevent blood loss, and minimize blood transfusion with the overall goal of improving patient outcomes. ${ }^{17}$ The success of these programs has helped reduce the overall rate of RBC transfusion and improve clinical outcomes. The network of Ontario Transfusion Coordinators (ONTraC), a province-wide multidisciplinary blood conservation program, was established in Ontario in 2002 with the support of the Ministry of Health and Long-Term Care. The central goal of this program is to promote blood conservation and alternative treatments to transfusion of RBCs. ${ }^{49}$ Transfusion coordinators were placed in 25 hospitals in the province, and the multidisciplinary team, which includes anesthesiologists, nurse practitioners, surgeons, perfusionists, and laboratory technologists among others, focuses primarily on increasing preoperative $\mathrm{Hb}$ levels by management of anemia (i.e., treatment with oral and intravenous iron and erythropoietin). This initiative requires that the diagnosis of anemia occurs at a sufficiently early time prior to surgery to enable adequate treatment. Optimally, a lead time of three to four weeks is required. The program also focuses on minimizing bleeding during surgery through use of antifibrinolytic therapy, topical hemostatic agents, meticulous attention to surgical hemostasis, and cell salvage. Repeated education about the appropriate indications for transfusion has been essential. A key task was to develop blood management champions. These champions become the leaders who promote the achievement of clinical excellence and optimal patient blood management. Through the coordinated efforts of its multidisciplinary members, ONTraC has shown an overall reduction in the incidence of blood transfusion in targeted patient populations, including patients undergoing hip and knee arthroplasty and coronary artery bypass grafting (Fig. 3). These overall reductions in transfusion rates have been associated with reduced length of hospital stay and infection rates (Table 1). The data provide evidence in support of the hypothesis that a patient

\section{Measured Reduction in Transfusion Rates in Ontario Derived from the ONTraC Database}

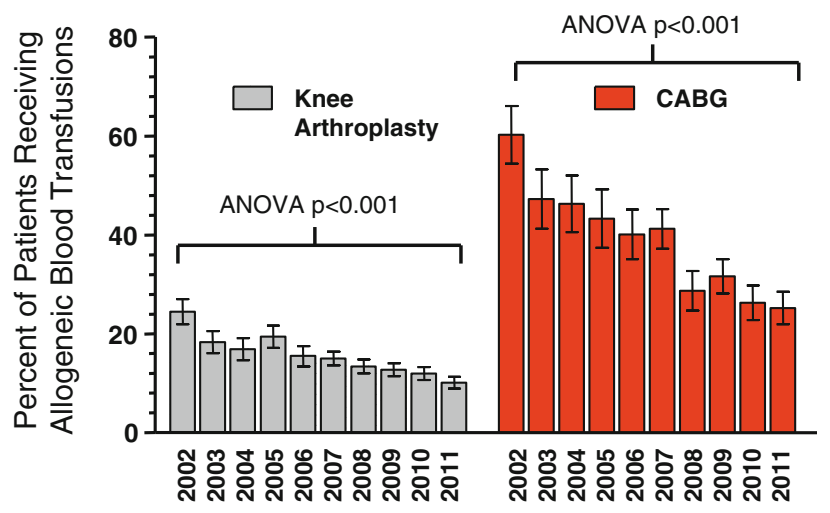

Fig. 3 Previously unpublished data from the network of Ontario Transfusion Coordinators (ONTraC) showing a reduction in red blood cell transfusion for knee arthroplasty and coronary artery bypass grafting (CABG) [mean (standard deviation)]. Transfusion rates decreased from $24.5 \%$ to $10.1 \%$ for knee surgery and from $60.2 \%$ to $25.2 \%$ for CABG surgery from 2002 to 2011 (ANOVA, $P<0.0001$ for both) 


\section{Preoperative and Nadir Hemoglobin}

Levels in ONTraC Patients (2010)

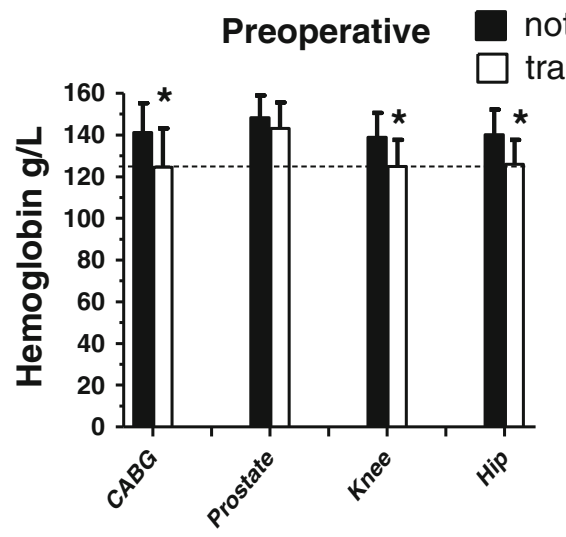

Nadir

transfused

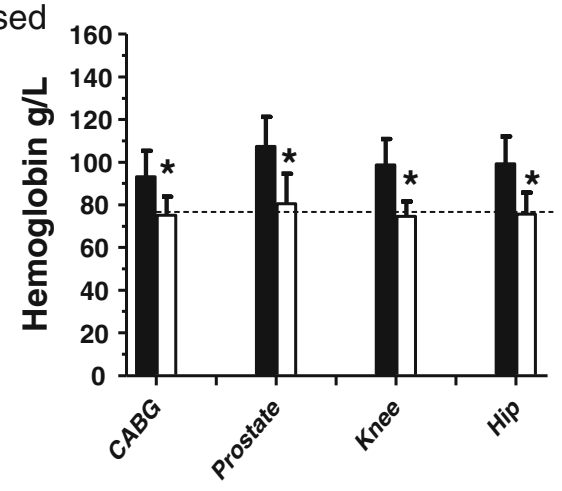

$\mathrm{p}<0.001$ transfused vs. not transfused

Fig. 4 Previously unpublished data from the network of Ontario Transfusion Coordinators (ONTraC) showing preoperative and postoperative nadir hemoglobin values in patients who were not transfused (black bars) and those who were transfused with red blood cells (white bars) for coronary artery bypass grafting (CABG), radical prostatectomy, and knee or hip arthroplasty surgery. The preoperative and nadir postoperative hemoglobin levels were significantly lower in patients who received a red blood cell transfusion than in those who did not receive a transfusion. The data suggest that a preoperative hemoglobin level $<130 \mathrm{~g} \cdot \mathrm{L}^{-1}$ represents a treatable target to avoid nadir hemoglobin levels requiring transfusion after surgery [mean (standard deviation) are compared by $t$ test]

Table 1 Impact of transfusion on LOS and infection rate

\begin{tabular}{lllll}
\hline Clinical Outcome & & Transfused & Not transfused & $P(t$ test $)$ \\
\hline LOS in days; mean (SD) & Knee & $7.9(13.3)$ & $6.1(16.2)$ & $5.8(13.9)$ \\
& Hip & $7.6(9.3)$ & $7.2(11.4)$ & 0.05 \\
Postoperative infections & CABG & $11.8(21.6)$ & $1.1 \%$ & 0.034 \\
& Knee & $1.7 \%$ & $1.9 \%$ & NA \\
& Hip & $5.4 \%$ & $3.4 \%$ & NA \\
\hline
\end{tabular}

(Infections included incision-site infections, deep surgical wound infections, septicemia, pneumonia, urinary tract infections, bone/joint infections, other. All had fever, positive cultures, and were treated with antibiotics.) LOS = length of stay; SD = standard deviation; NA = not assessed; $\mathrm{CABG}=$ coronary artery bypass grafting

Table 2 Effect of preoperative $\mathrm{Hb}$ on transfusion rates after total knee or hip arthroplasty or CABG

\begin{tabular}{llll}
\hline Preoperative $\mathrm{Hb}$ & \multicolumn{4}{l}{ Percent transfused } \\
\cline { 2 - 4 } & Knee & Hip & CABG \\
\hline $\mathrm{Hb}<130 \mathrm{~g} \cdot \mathrm{L}^{-1}$ & $26.0 \%$ & $31.5 \%$ & $56.3 \%$ \\
$\mathrm{Hb}>130 \mathrm{~g} \cdot \mathrm{L}^{-1}$ & $6.1 \%$ & $7.3 \%$ & $16.5 \%$ \\
$\mathrm{Hb}>140 \mathrm{~g} \cdot \mathrm{L}^{-1}$ & $3.7 \%$ & $3.7 \%$ & $10.2 \%$ \\
$P$ (ANOVA) & $<0.0001$ & $<0.0001$ & $<0.0001$ \\
\hline
\end{tabular}

$\mathrm{Hb}=$ hemoglobin concentration; $\mathrm{CABG}=$ coronary artery bypass grafting; ANOVA = analysis of variance

blood management program can improve patient outcome and therefore enhance safety for anemic patients undergoing surgical procedures.
Table 3 Effect of having a long lead time to optimize preoperative treatment of anemia

\begin{tabular}{lll}
\hline Lead time & \multicolumn{2}{l}{ Percent Transfused } \\
\cline { 2 - 3 } & Knee & CABG \\
\hline$<7$ days & $10.4 \%$ & $41.3 \%$ \\
$7-14$ days & $9.8 \%$ & $31.4 \%$ \\
$15-21$ days & $8.6 \%$ & $25.0 \%$ \\
$>21$ days & $7.3 \%$ & $22.8 \%$ \\
$P$ (ANOVA) & $<0.0001$ & $<0.0001$
\end{tabular}

$\mathrm{CABG}=$ coronary artery bypass grafting; $\mathrm{ANOVA}=$ analysis of variance

The potential for improved patient safety can be shown by the prevalence of anemia in our surgical patient population. The prevalence of anemia in these patients has been 
estimated to be from $20-50 \%$ for different surgical patient populations. ${ }^{13,17}$ The finding that mild levels of anemia can increase patient mortality ${ }^{5,7}$ has emphasized the need to assess the impact of treating these patients. In the ONTraC database, patients with a $\mathrm{Hb}$ level $<130 \mathrm{~g} \cdot \mathrm{L}^{-1}$ experienced an increase in transfusion rate and a lower postoperative $\mathrm{Hb}$ level compared with patients with a $\mathrm{Hb}$ level $>130 \mathrm{~g} \cdot \mathrm{L}^{-1}$ (Fig. 4, Table 2). In addition, the percentage of transfused patients decreased significantly with increasing lead time for preoperative assessment and anemia treatment (Table 3). Collectively, these data suggest that both transfusion and adverse patient outcomes should be reduced if adequate time is provided to treat anemia and increase $\mathrm{Hb}$ preoperatively.

\section{Conclusions}

Anemia and RBC transfusion are both associated with increased morbidity and mortality. Anemia is a prevalent problem in cardiac and non-cardiac surgical patients. A significant proportion of anemic patients may respond to available therapies to treat low $\mathrm{Hb}$ levels effectively. Evidence of benefit from RBC transfusion is hard to find, and most benefit from RBC transfusion is assumed and not scientifically proven. Some patients will benefit, but we need to be better able to identify who these patients are. It is not necessarily better to give more blood, and many transfusions are probably unnecessary. Multidisciplinary and multimodal patient blood management programs are able to effect treatment of anemia, reduce blood transfusions, and improve patient outcomes. Improving the management of anemic patients by 1) identifying an appropriate $\mathrm{Hb}$ threshold for transfusion in specific patient populations; 2) identifying patient-specific biomarkers of anemia-induced tissue hypoxia; and 3) instituting patient blood management programs, may further improve patient outcomes and the "safety" of anesthesia and surgery.

\section{Key points}

- Acute and chronic anemia are independent predictors of adverse patient outcomes, including increased mortality, and may therefore jeopardize patient safety.

- The mechanism(s) of anemia-induced morbidity and mortality are complex and include inadequate tissue oxygen delivery.

- Current therapies to treat anemia, including red blood cell transfusion, erythrocyte stimulating agents, and blood substitutes, have not been shown to improve patient outcomes.

- A blood conservation program (e.g., ONTraC) can reduce red blood cell transfusion and improve patient outcomes by reducing length of hospital stay and rates of perioperative infection.

- New multimodal approaches to the management of anemia may continue to improve perioperative patient outcomes and safety.

Supported by the Canadian Anesthesiologists' Society, Canadian Anesthesia Research Foundation, The St. Michael's Hospital Centre of Excellence in Patient Blood Management and Hemostasis, and the Departments of Anesthesia and Medicine, Division of Hematology, St. Michael's Hospital, University of Toronto.

Dr. Hare has received funding from Forest Research Inc. for basic science studies and salary support for his role in the St. Michael's Hospital Centre of Excellence for Patient Blood Management and Hemostasis from Johnson \& Johnson Inc. Drs. Hare and Mazer are supported by University of Toronto, Department of Anesthesia Merit Awards.

The authors gratefully acknowledge the support of the Transfusion Coordinators within the network of Ontario Transfusion Coordinators (ONTraC).

Competing interests None declared.

\section{References}

1. Eagle CJ, Davies JM. Current models of "quality"-an introduction for anaesthetists. Can J Anaesth 1993; 40: 851-62.

2. Haller G, Stoelwinder J, Myles PS, McNeil J. Quality and safety indicators in anesthesia: a systematic review. Anesthesiology 2009; 110: 1158-75.

3. Shander A, Javidroozi M, Ozawa S, Hare GM. What is really dangerous: anaemia or transfusion? $\mathrm{Br} \mathrm{J}$ Anaesth 2011; 107(Suppl 1): i41-59.

4. Stoltzfus RJ. Iron deficiency: global prevalence and consequences. Food Nutr Bull 2003; 24(4 Suppl): S99-103.

5. Musallam KM, Tamim HM, Richards T, et al. Preoperative anaemia and postoperative outcomes in non-cardiac surgery: a retrospective cohort study. Lancet 2011; 378: 1396-407.

6. Saleh E, McClelland DB, Hay A, Semple D, Walsh TS. Prevalence of anaemia before major joint arthroplasty and the potential impact of preoperative investigation and correction on perioperative blood transfusions. Br J Anaesth 2007; 99: 801-8.

7. Hung $M$, Besser M, Sharples LD, Nair SK, Klein AA. The prevalence and association with transfusion, intensive care unit stay and mortality of pre-operative anaemia in a cohort of cardiac surgery patients. Anaesthesia 2011; 66: 812-8.

8. Goodnough LT, Maniatis A, Earnshaw P, et al. Detection, evaluation, and management of preoperative anaemia in the elective orthopaedic surgical patient: NATA guidelines. Br J Anaesth 2011; 106: 13-22.

9. Karkouti K, Wijeysundera DN. Reducing Bleeding in Cardiac Surgery $(R B C)$ Investigators. Risk associated with preoperative anemia in cardiac surgery: a multicenter cohort study. Circulation 2008; 117: 478-84.

10. Kulier A, Levin J, Moser R, et al. Impact of preoperative anemia on outcome in patients undergoing coronary artery bypass graft surgery. Circulation 2007; 116: 471-9.

11. El Beheiry MH, Heximer SP, Voigtlaender-Bolz J, et al. Metoprolol impairs resistance artery function in mice. J Appl Physiol 2011; 111: 1125-33.

12. Ragoonanan TE, Beattie WS, Mazer CD, et al. Metoprolol reduces cerebral tissue oxygen tension after acute hemodilution in rats. Anesthesiology 2009; 111: 988-1000. 
13. Beattie WS, Karkouti K, Wijeysundera DN, Tait G. Risk associated with preoperative anemia in noncardiac surgery: a singlecenter cohort study. Anesthesiology 2009; 110: 574-81.

14. Beattie WS, Wijeysundera DN, Karkouti K, et al. Acute surgical anemia influences the cardioprotective effects of beta-blockade: a single-center, propensity-matched cohort study. Anesthesiology 2010; 112: 25-33.

15. Beattie WS, Wijeysundera D, Tait G, et al. Mechanisms of perioperative stroke: a multi-disciplinary translational research program. Presented at the Meeting of the Canadian Anesthesiologists Society 2012: 1344654 (abstract).

16. Feagan BG, Wong CJ, Kirkley A, et al. Erythropoietin with iron supplementation to prevent allogeneic blood transfusion in total hip joint arthroplasty. A randomized, controlled trial. Ann Intern Med 2000; 133: 845-54.

17. Shander A, Van Aken H, Colomina MJ, et al. Patient blood management in Europe. Br J Anaesth 2012; 109: 55-68.

18. Bohlius J, Wilson J, Seidenfeld J, et al. Erythropoietin or darbepoetin for patients with cancer. Cochrane Database Syst Rev 2006; 3: CD003407.

19. Pfeffer MA, Burdmann EA, Chen CY, et al. A trial of darbepoetin alfa in type 2 diabetes and chronic kidney disease. N Engl J Med 2009; 361: 2019-32.

20. Carson JL, Poses RM, Spence RK, Bonavita G. Severity of anaemia and operative mortality and morbidity. Lancet 1988; 1 : 727-9.

21. Tsui AK, Marsden PA, Mazer CD, et al. Priming of hypoxiainducible factor by neuronal nitric oxide synthase is essential for adaptive responses to severe anemia. Proc Natl Acad Sci USA 2011; 108: 17544-9.

22. Zarychanski $R$, Houston DS. Anemia of chronic disease: a harmful disorder or an adaptive, beneficial response? CMAJ 2008; 179: 333-7.

23. Hare GM, Tsui AK, McLaren AT, Ragoonanan TE, Yu J, Mazer $C D$. Anemia and cerebral outcomes: many questions, fewer answers. Anesth Analg 2008; 107: 1356-70.

24. Weiskopf RB, Viele MK, Feiner J, et al. Human cardiovascular and metabolic response to acute, severe isovolemic anemia. JAMA 1998; 279: 217-21.

25. McLaren AT, Marsden PA, Mazer CD, et al. Increased expression of HIF-1\{alpha\}, nNOS, and VEGF in the cerebral cortex of anemic rats. Am J Physiol Regul Integr Comp Physiol 2007; 292: R403-14.

26. Semenza GL. Regulation of mammalian $\mathrm{O} 2$ homeostasis by hypoxia-inducible factor 1 . Annu Rev Cell Dev Biol 1999; 15: 551-78.

27. El Hasnaoui-Saadani R, Pichon A, Marchant D, et al. Cerebral adaptations to chronic anemia in a model of erythropoietin-deficient mice exposed to hypoxia. Am J Physiol Regul Integr Comp Physiol 2009; 296: R801-11.

28. Li M, Bertout JA, Ratcliffe SJ, Eckenhoff MF, Simon MC, Floyd $T F$. Acute anemia elicits cognitive dysfunction and evidence of cerebral cellular hypoxia in older rats with systemic hypertension. Anesthesiology 2010; 113: 845-58.

29. Natanson C, Kern SJ, Lurie P, Banks SM, Wolfe SM. Cell-free hemoglobin-based blood substitutes and risk of myocardial infarction and death: a meta-analysis. JAMA 2008; 299: 2304-12.

30. Alghamdi AA, Albanna MJ, Guru V, Brister SJ. Does the use of erythropoietin reduce the risk of exposure to allogeneic blood transfusion in cardiac surgery? A systematic review and metaanalysis. J Card Surg 2006; 21: 320-6.

31. de Andrade JR, Frei D, Guilfoyle M. Integrated analysis of thrombotic/vascular event occurrence in epoetin alfa-treated patients undergoing major, elective orthopedic surgery. Orthopedics 1999; 22(1 Suppl): s113-8.

32. Dai $J, T u W$, Yang $Z$, Lin $R$. Case report: Intraoperative management of extreme hemodilution in a patient with a severed axillary artery. Anesth Analg 2010; 111: 1204-6.

33. Vincent $J L$. Indications for blood transfusions: too complex to base on a single number? Ann Intern Med 2012; 157: 71-2.

34. Weiskopf $R B$. Emergency transfusion for acute severe anemia: a calculated risk. Anesth Analg 2010; 111: 1088-92.

35. Smith J, Bricker S, Putnam B. Tissue oxygen saturation predicts the need for early blood transfusion in trauma patients. Am Surg 2008; 74: 1006-11.

36. Creteur J, Neves AP, Vincent JL. Near-infrared spectroscopy technique to evaluate the effects of red blood cell transfusion on tissue oxygenation. Crit Care 2009; 13(Suppl 5): S11.

37. Dhar R, Zazulia AR, Videen TO, Zipfel GJ, Derdeyn CP, Diringer $M N$. Red blood cell transfusion increases cerebral oxygen delivery in anemic patients with subarachnoid hemorrhage. Stroke 2009; 40: 3039-44.

38. Zygun DA, Nortje J, Hutchinson PJ, Timofeev I, Menon DK, Gupta AK. The effect of red blood cell transfusion on cerebral oxygenation and metabolism after severe traumatic brain injury. Crit Care Med 2009; 37: 1074-8.

39. Arellano-Orden V, Leal-Noval SR, Cayuela A, et al. Gender influences cerebral oxygenation after red blood cell transfusion in patients with severe traumatic brain injury. Neurocrit Care 2011; 14: 18-23.

40. Hare GM, Mu A, Romaschin A, et al. Plasma methemoglobin as a potential biomarker of anemic stress in humans. Can J Anesth 2012; 59: 348-56.

41. Tsui AK, Dattani ND, Marsden PA, et al. Reassessing the risk of hemodilutional anemia: some new pieces to an old puzzle. Can J Anesth 2010; 57: 779-91.

42. Hebert PC, Wells G, Blajchman MA, et al. A multicenter, randomized, controlled clinical trial of transfusion requirements in critical care. Canadian Critical Care Trials Group. N Engl J Med 1999; 340: 409-17.

43. Carson JL, Grossman BJ, Kleinman S, et al. Red blood cell transfusion: a clinical practice guideline from the AABB. Ann Intern Med 2012; E-429.

44. Hebert PC, Yetisir E, Martin C, et al. Is a low transfusion threshold safe in critically ill patients with cardiovascular diseases? Crit Care Med 2001; 29: 227-34.

45. McIntyre LA, Fergusson DA, Hutchison JS, et al. Effect of a liberal versus restrictive transfusion strategy on mortality in patients with moderate to severe head injury. Neurocrit Care 2006; 5: 4-9.

46. Carson JL, Terrin ML, Noveck $H$, et al. Liberal or restrictive transfusion in high-risk patients after hip surgery. N Engl J Med 2011; 365: 2453-62.

47. Hajjar LA, Vincent JL, Galas FR, et al. Transfusion requirements after cardiac surgery: the TRACS randomized controlled trial. JAMA 2010; 304: 1559-67.

48. Shehata $N$, Burns LA, Nathan $H$, et al. A randomized controlled pilot study of adherence to transfusion strategies in cardiac surgery. Transfusion 2012; 52: 91-9.

49. Freedman J, Luke K, Escobar M, Vernich L, Chiavetta JA. Experience of a network of transfusion coordinators for blood conservation (Ontario Transfusion Coordinators [ONTraC]). Transfusion 2008; 48: 237-50. 